\title{
Monocyte chemoattractant protein-1 promoter polymorphism and plasma levels in alzheimer's disease
}

\author{
Elisa Porcellini ${ }^{*}$, Manuela lanni ${ }^{1}$, llaria Carbone ${ }^{1}$, Massimo Franceschi ${ }^{2}$ and Federico Licastro ${ }^{1}$
}

\begin{abstract}
Background: Neurodegenerative disorders such Alzheimer's disease (AD) are often characterized by senile plaques and neurofibrillary tangle. In addition, reactive astrogliosis, microglia activation and a chronic inflammation are found in AD brain. Activated microglia has been reported to express a large number of beta chemokines including monocyte chemoattractant protein-1 (MCP-1). The potential role of MCP-1 in AD pathogenesis is supported by the over expression of MCP-1 associated with an increase of amyloid deposition in transgenic mice. MCP-1 protein may be regulated by a single nucleotide polymorphism (SNP) occurring at position -2518 of the MCP-1 gene promoter. In this paper we correlated the A-2518G MCP-1 SNP distribution in three different populations: AD, control and MCl (mild cognitive impairment) population to evaluate whether this SNP might be a risk factor for AD or for MCI-AD conversion. MCP-1 plasma levels were also measured and correlated to the cognitive impairment (CIND) and AD risk.

Results: No differences in genotype distribution and allele frequencies of A-2518G MCP-1 SNP among AD patients, $\mathrm{MCl}$ subjects and controls were observed even after APOEe4 variation adjustment with logistic regression. However in $\mathrm{MCl}$ subjects, followed up for two years, this SNP appears to influence the progression of the disease; being the G allele slightly more frequent in $\mathrm{MCl}$ patients that developed AD. MCP-1 plasma levels were different among CIND (cognitive impairment but no dementia), AD and controls. The MCP-1 A-2518G promoter polymorphism did not affect MCP-1 plasma levels within the three populations.
\end{abstract}

Conclusions: MCP-1 G allele did not affect the risk of AD, but slightly influenced $\mathrm{MCl}$ conversion to $\mathrm{AD}$ and MCP-1 plasma levels were increased in subjects with preclinical AD.

Keywords: Alzheimer's disease, MCP-1 promoter polymorphism, MCP-1 plasma levels, MCI -AD conversion

\section{Background}

Alzheimer's disease (AD) is the most common form of adult-onset dementia. Pathological hallmarks of AD include amyloid deposits rich in $\beta$-amyloid $(\mathrm{A} \beta$ ) peptide, neurofibrillary tangles composed of hyperphosphorylated tau and the occurrence of activated microglia [1].

Etiopathogenetic mechanisms associated with agerelated cognitive decline and $\mathrm{AD}$ are complex and still largely unclear. However, both genetic and environmental factors are implicated in the pathogenesis of the disease [2-5].

\footnotetext{
*Correspondence: elisa.porcellini3@unibo.it

'DIMES, School of Medicine, University of Bologna, Via S. Giacomo 14, 40126, Bologna, Italy

Full list of author information is available at the end of the article
}

A substantial literature has suggested the involvement of several processes in $\mathrm{AD}$ onset, such as inflammation, plaque deposition, oxidative stress, cholesterol homeostasis and endothelial dysfunction [6-9].

A number of inflammatory mediators associated with amyloid deposits such as Interleukin-1 (IL-1), IL-6, transforming growth factor (TGF- $\beta$ ), TNF- $\alpha$, acute phase proteins for instance $\alpha-1$ antichymotrypisn (ACT) and $\alpha_{2}$-macroglobulin, and several complement factors have been detected in AD brains [10,11].

Inflammatory cytokines are produced by activated microglia and astrocytes and these molecules are able to stimulate the phagocitic activity of microglia [12]. Activated microglia has been reported to express a large number of beta chemokines including monocyte chemoattractant protein-1 (MCP-1) [13,14]. 
MCP-1, produced by neurons and glial cells, is a chemokine that, by regulating monocyte chemotaxis and endothelial activation, modulates inflammatory processes. The potential role of MCP-1 in AD pathogenesis is supported by the over expression of MCP-1 associated with an increase of Abeta deposition in Amyloid precursor protein (APP) transgenic mice [15]. In addition higher MCP-1 levels in cerebro spinal fluid (CSF) of AD patients than matched controls have been reported [16]. This latter finding has been confirmed by an independent recent study showing that CSF levels of MCP-1 were significant increased in subjects with $\mathrm{AD}$ compared to healthy controls [17]. Moreover, a recent study showed that elevated MCP-1 CSF levels were associated with an higher annual decrease of MMSE score in AD patients; these findings suggested that elevated CSF MCP-1 was associated with an accelerated rate of cognitive decline [18].

Data regarding $\mathrm{MCP}-1$ plasma levels are conflicting. Several Authors showed that MCP-1 levels were elevated in $\mathrm{AD}$ patients or subjects with mild cognitive impairment (MCI) [19,20]. These data were not confirmed by other studies reporting no association between MCP-1 plasma levels and $\mathrm{AD}[12,21]$.

It has been shown that serum levels and biological activity of the MCP-1 protein may be regulated by a single nucleotide polymorphism (SNP) occurring at position -2518 of the MCP-1 gene promoter [22,23]. Several studied described this SNP as a risk factor for $\mathrm{AD}$ but results are not always concordant being this polymorphism differentially distributed in different populations [21,24-27].

Here we present data on MCP-1 A-2518G polymorphism in $\mathrm{AD}$ patients, in subjects with $\mathrm{MCI}$ and in a healthy elderly control population and its association with the risk of $\mathrm{AD}$ or $\mathrm{MCI}$.

MCP-1 plasma levels were also measured in AD patients, subjects with cognitive impairment but no dementia (CIND) and healthy elderly followed up for five years and levels of MCP-1 were correlated with cognitive deterioration.

\section{Results}

As reported in Table 1, no difference in genotype distribution and allele frequencies of A-2518G MCP-1 SNP among $\mathrm{AD}$ patients, MCI subjects and controls (CTR) were observed $\left(\mathrm{AD}\right.$ vs CTR $\mathrm{X}^{2}=0.11, \mathrm{p}=0.994$; CTR vs MCI $\chi^{2}=3.633, \mathrm{p}=0.163 ; \mathrm{AD}$ vs $\mathrm{MCI} \mathrm{X}^{2}=3.942$, $\mathrm{p}=0.139$ ). An agarose gel with the three different pattern of bands (representing the three different genotypes) was showed in Figure 1.

Logistic regression analysis regarding MCP-1 genotype distribution adjusted for age and APOEe4 was applied to these populations and results were not statistically
Table 1 Genotype distribution and allele frequency of the A-2518G MCP-1 promoter polymorphism in patients with probable AD, patients with $\mathrm{MCl}$ and controls (CTR) from Northern Italy

\begin{tabular}{lccccc}
\hline & AA & AG & GG & Allele A & Allele G \\
\hline & $(n) \%$ & $(n) \%$ & $(n) \%$ & $(n) \%$ & $(n) \%$ \\
$\mathrm{AD}(\mathrm{n}=291)$ & $(139) 47.8$ & $(130) 44.7$ & $(22) 7.6$ & $(269) 92.4$ & $(152) 52.2$ \\
$\mathrm{MCl}(\mathrm{n}=88)$ & $(49) 55.7$ & $(37) 42.0$ & $(2) 2.3$ & $(86) 97.7$ & $(38) 43.2$ \\
$\mathrm{CTR}(\mathrm{n}=146)$ & $(69) 47.3$ & $(66) 45.2$ & $(11) 7.5$ & $(135) 92.5$ & $(77) 52.7$ \\
\hline
\end{tabular}

Statistics.

$A D$ vs CTR (genotypic distribution): Pearson $x^{2}=0.11, p=0.994$; logistic regression adjusted for age and APOE e4 $p=0.713 \mathrm{c.i}$ 95\% (0.981-1.013).

CTR vs $\mathrm{MCl}$ (genotypic distribution): Pearson $\mathrm{x}^{2}=3.633, \mathrm{p}=0.163$; logistic regression adjusted for age and APOE e4 $p=0.988 \mathrm{c.i}$ 95\% (0.970-1.007)

$A D$ vs $\mathrm{MCl}$ (genotypic distribution): Pearson $\mathrm{X}^{2}=3.942, \mathrm{p}=0.139$; logistic regression adjusted for age and APOE e4 $p=0.299 \mathrm{c.i}$ 95\% (0.994-1.018).

significant; therefore age and APOE\&4 presence did not affect MCP-1 genotype distribution (AD vs CTR $\mathrm{p}=0.713$, AD vs MCI $\mathrm{p}=0.299$, MCI vs CTR $\mathrm{p}=0.988$ ) and MCP-1 genotype was not an independent risk factor for $\mathrm{AD}$ or $\mathrm{MCI}$.

MCI patients were followed up for 2 years and cognitive performances were detected at the end of the study. Among the MCI group, 38 subjects evolved to AD, and 45 did not. Genotype distribution and allele frequency of MCI patients converting to AD compared to those remaining MCI were described in Table 2. The G allele was slightly more frequent in MCI patients that converted to $\mathrm{AD}$ after 2 years than in those remaining

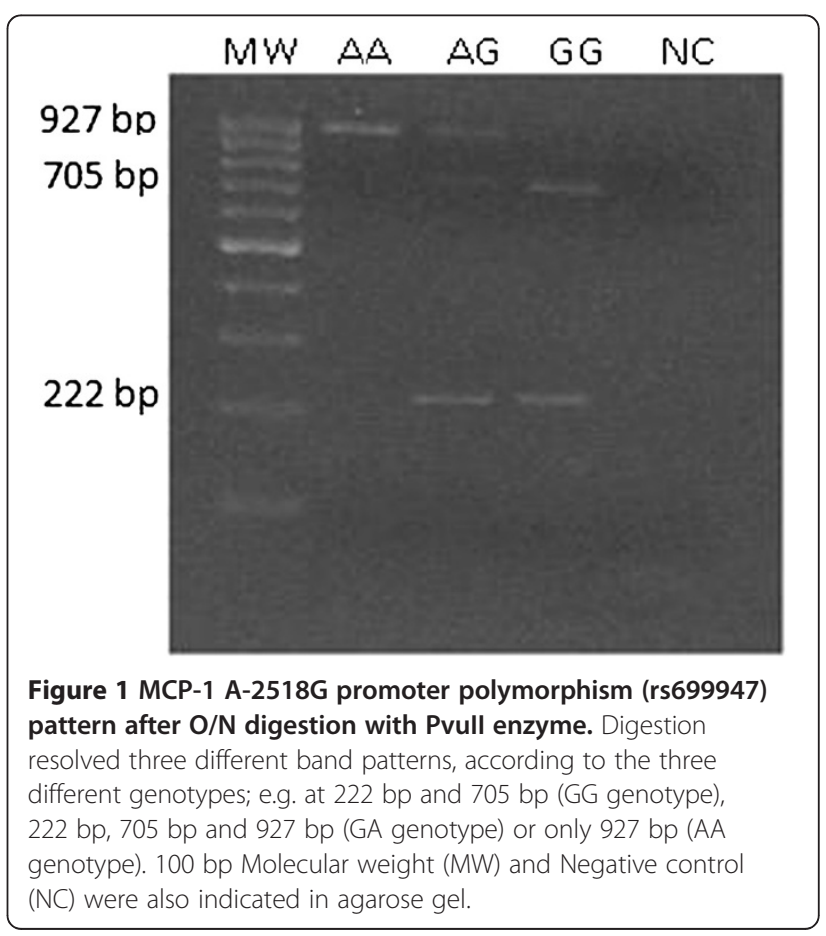


Table 2 Genotype distribution and allele frequency of $\mathrm{MCl}$ patients converting to AD compared to those remaining $\mathrm{MCl}$

\begin{tabular}{lccccc}
\hline & AA $(\mathbf{n}) \%$ & AG (n) \% & GG (n) \% & Allele A (n) \% & Allele G (n) \% \\
\hline $\mathrm{MCl}->\mathrm{AD}(\mathrm{n}=38)$ & $(19) 50.0$ & $(18) 47.4$ & $(1) 2.4$ & $(37) 97.4$ & $(19) 47.4$ \\
$\mathrm{MCl}=\mathrm{MCl}(\mathrm{n}=45)$ & $(28) 62.2$ & $(17) 37.8$ & (0) 0 & (45) 100 & $(17) 37.8$ \\
\hline
\end{tabular}

Pearson $\mathrm{x}^{2}=2.117, \mathrm{p}=0.337$.

Logistic regression analysis adjusted for Age and APOE e4 : G allele p=0.137 c.i 95\% (0.948-1.007).

$\mathrm{MCI}$, however the difference was not statistically significant $\left(x^{2}=2.117, p=0.337\right)$. This difference was not statistically significant also after logistic regression adjusted for age and APOE\&4 presence $(\mathrm{p}=0.137)$.

MCP-1 plasma levels were also detected in AD patients $(n=87)$, controls $(n=34)$ and CIND subjects $(n=24)$, as shown in Figure 2.

AD patients showed lower MCP-1 levels $(43 \mathrm{pg} / \mathrm{ml} \pm 28)$ than CIND $(88 \mathrm{pg} / \mathrm{ml} \pm 38)$ and controls $(66 \mathrm{pg} / \mathrm{ml} \pm 50)$, differences in MCP-1 levels among the three groups were statistically significant and elevated in CIND (ANOVA test $\mathrm{F}=15.695 \mathrm{p}=0.0001$; Post hoc comparison: $\mathrm{AD}$ vs $\mathrm{CTR}$ $\mathrm{p}=0.003$; $\mathrm{AD}$ vs $\mathrm{CIND} \mathrm{p}=0.0001$; CIND vs CTR $\mathrm{p}=0.024$ ).

MCP-1 plasma levels were also valuated in $\mathrm{AD}$ patients stratified according to MMSE score. Severe AD (MMSE score <14), showed apparently higher MCP-1 levels $(51 \mathrm{pg} / \mathrm{ml} \pm 34)$ than mild AD $(41 \mathrm{pg} / \mathrm{ml} \pm 27)$ (MMSE score $>14$ ), but differences were not statistically significant.

In addition, MCP-1 plasma levels were correlated with the MCP-1 A-2518G promoter polymorphism. Table 3 shows MCP-1 plasma levels in AD, CIND and controls after the stratification for the three MCP-1 A-2518G different genotypes. It is interesting to note that $\mathrm{AD}$ patients and controls carrying $\mathrm{AA}$ genotype showed lower MCP-1 plasma levels than CIND ( $\mathrm{F}=7.811 \mathrm{p}=0.001)$. However, MCP-1 genotypes or alleles did not affected MCP-1 plasma levels within each population.

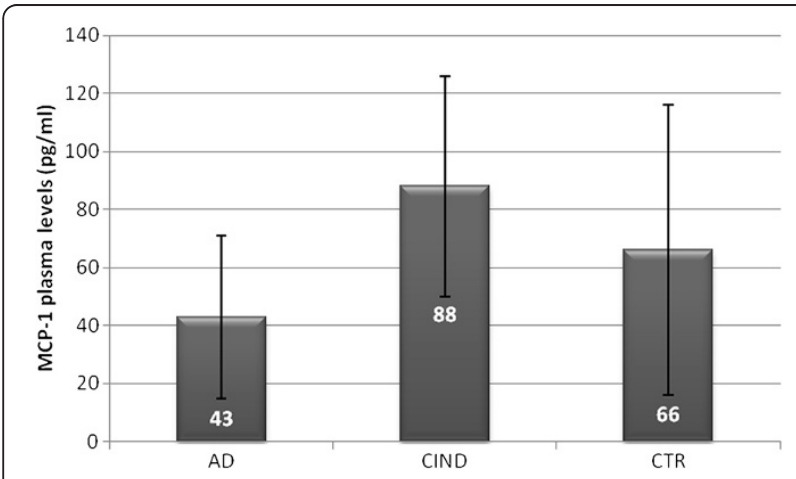

Figure 2 MCP-1 plasma levels $(\mathrm{pg} / \mathrm{ml})$ in patient with $A D, C I N D$ and Controls. ANOVA, $F=15.695 p=0.0001$

\section{Discussion}

In AD brain, the presence of amyloid deposition, neurofibrillary tangles, activated microglia and astrocitosis may stimulate a local and a chronic inflammatory process that involves the synthesis and the release of numerous factors such as cytokines, chemokines and inflammatory mediators [13]. However, systemic inflammation is also detectable in peripheral blood of $\mathrm{AD}$ as illustrated by the elevation of some acute phase proteins or cytokines [28].

In addition, a large number of genetic variations in genes coding for pro- or anti inflammatory molecules have been associated with the risk of dementia or cognitive decline $[4,5,29,30]$.

In the present study the distribution of MCP-1 A-2518G SNP in the promoter region of MCP-1 gene and plasma levels of MCP-1 in $\mathrm{AD}$ or subjects with preclinical AD were investigated.

Our findings suggested that the MCP-1 SNP promoter was not a risk factor for $\mathrm{AD}$ being the SNP equally distributed in $\mathrm{AD}$ patients and controls. Our results confirmed data from different case-controls studies reporting no association between this SNP and the risk of AD [21,24-26]. On the other hand, a different Italian study by Pola et al. showed an increased representation of GG genotype in AD patients [27]. Our data were not able to confirm this latter study. Differences in SNP distribution across case/controls studies might be explained by the great ethnic variability of this SNP, since the $\mathrm{G}$ allele is found differentially present in Caucasian, Americans or Asian population [23]. Differences between present investigation and Pola's study might be explained by different clinical AD or CTR selection.

Then, we studied the distribution of MCP-1 A-2815G SNP in a MCI population followed up for two years in order to evaluated the effect of this SNP on the progression of the disease. No data on the effect of this SNP in $\mathrm{MCI} / \mathrm{AD}$ conversion is available in literature. The G

Table 3 MCP-1 plasma levels (mean \pm s.d) in AD patients, CIND and controls

\begin{tabular}{lcccccc}
\hline & AA & AG & GG & Allele A & Allele G & P \\
\hline $\mathrm{AD}(\mathrm{n}=73)$ & $44 \pm 32$ & $41 \pm 28$ & $39 \pm 6$ & $42 \pm 29$ & $41 \pm 26$ & 0.910 \\
$\mathrm{CIND}(\mathrm{n}=20)$ & $93 \pm 33$ & $82 \pm 38$ & $66.64 \pm 35$ & $86 \pm 36$ & $80 \pm 37$ & 0.427 \\
$\mathrm{CTR}(\mathrm{n}=15)$ & $44 \pm 22$ & $94 \pm 113$ & $74.37 \pm 50$ & $62 \pm 69$ & $91 \pm 101$ & 0.697 \\
\hline
\end{tabular}


allele frequency was slightly higher in MCI showing a further cognitive deterioration and converted to $\mathrm{AD}$. However, this difference was not statistically significant. This effect might be partially ascribed to the small size of MCI population and further investigations are needed to better understand the influence of this SNP in cognitive deterioration and progression to $\mathrm{AD}$.

High levels of pro-(or anti) inflammatory cytokines and chemokines have been found associated with $A D$ [28]. The main role of these molecules and in particular of MCP-1 is supported by the observation that this latter molecule can induce chemotaxis of monocytes and microglia, contributing to pathological gliosis associated with AD [31,32]. Relevance of MCP-1 in AD was suggested by data showing a significantly enhanced immunoreactivity for MCP-1 in neurons, astrocytes and microglia from AD brains [33]. Moreover, several studies reported that MCP-1 plasma or CSF levels were higher in AD patients or MCI than controls [19,20,31].

We found statistically differences in MCP-1 plasma levels among $\mathrm{AD}, \mathrm{CIND}$ and controls, being MCP-1 levels higher in CIND than those in AD patients and/or controls.

In our study we measured MCP-1 levels by using BIOPlex multi Cytokines platform. Our results showed that MCP-1 absolute levels, in $\mathrm{pg} / \mathrm{ml}$, from $\mathrm{AD}, \mathrm{CIND}$ or CTR, were lower than those found in other reports. Different techniques for MCP-1 detection may partially explain why we did not confirm increased MCP-1 plasma levels in AD. On the other hand, our data agree with the only study that used the same detection system used by us for MCP-1 levels [12]. Decreased level of peripheral MCP-1 levels along with increased CSF concentration of this chemokyne in $\mathrm{AD}$ may suggest an impaired MCP-1 turnover between these two compartments. Such an alteration may be not present in pre dementia conditions such as CIND since, increased levels of blood MCP-1 levels were observed in this population. However, further studies on a larger cohort of CIND or MCI subjects are needed to better define the role of blood MCP-1 in cognitive deterioration and $\mathrm{AD}$ developing and the use of blood MCP-1 as a potential marker for cognitive impairment.

MCP-1 expression might be under the control of A$2518 \mathrm{G}$ promoter SNP. This is supported by a study showing that the biallelic G/A polymorphism at position 2518 of the MCP-1 gene appears to influence the transcriptional activity MCP-1 gene [22]. In particular G allele seems to be associated with a higher MCP-1 production in a dose dependent manner where GG homozygous produce more MCP-1 than that from G/A heterozygous [22]. A previously reported study showed that MCP-1 serum levels were increased in AD patients positive for one or two $G$ alleles [21]. Our data did not confirm the above findings, since we did not find an increase of MCP-1 levels in AD G carrier patients. Accordingly, no effect of this SNP was observed on MCP-1 plasma levels from CIND or controls.

Our study presents some limitations due to the selection of subject with a different kind of pre-dementia condition: CIND and/or MCI. It is known that MCI, with clinical assessed symptoms and risk factors well described by Petersen $\mathrm{RC}$, are likely to progress to $\mathrm{AD}$ at a rate of approximately $12 \%$ per year [34]. On the other hand, subjects with CIND show heterogeneous risk factors only partially overlapping with those associated with MCI [35].

Data presented in our pilot study regarding the A2518G SNP distribution and MCP-1 plasma levels in cognitive deterioration need to be replicated in a homogeneous and larger MCI population to better understand the MCP-1 role in cognitve performance and deterioration.

\section{Conclusion}

Our findings suggest that MCP-1 G allele appears to slightly influence MCI conversion to AD and that MCP1 plasma levels are increased in preclinical AD such as subjects with CIND. These data implicate that MCP-1 genetic background and phenotypic expression might be associated to early mechanisms associated with neurodegeneration leading to dementia. However, due to the relatively small sample and the different pre-dementia condition subjects included in the present study, our data need to be confirmed in large and homogeneous population-based cohorts.

\section{Methods}

\section{Subjects}

The study included 291 patients with AD (mean age $=75.14 \pm 7.97)$, 88 patients with mild cognitive impairment $(\mathrm{MCI})$ (mean age=70.94 \pm 8.29 ), 20 CIND (mean age $=78.95 \pm 6.47$ ) and 148 healthy subjects (mean age $=$ $71.61 \pm 4.70)$.

Clinical diagnosis of probable $\mathrm{AD}$ was performed according standard clinical procedures and followed the NINCDS/ADRDA [36] and DSM-III-R criteria [37]. Diagnosis of probable AD was performed after patient evaluation by two independent physicians and according brain computerized tomography scan. Cognitive performances and alterations were measured by the mini mental state examination (MMSE).

AD patients were enrolled from Northern Italy at the Department of Neuroscience of Castellanza University (Milan, Italy).

MCI subjects were enrolled from the Department of Neurology, University of Brescia, Northern Italy. Diagnosis of MCI was performed according to current clinical criteria [38]. 
Subjects with CIND and non demented controls belonged to the "Conselice study of brain aging" [39].

$\mathrm{AD}$ patients, $\mathrm{MCI}$ and CIND subjects and controls were Caucasian and informed consent from each subject or a relative of each $\mathrm{AD}$ patient was obtained.

\section{DNA extraction and polymorphism detection}

DNA extraction from peripheral blood leukocytes were assessed as previously described [40].

The triallelic APOE ع2-4 polymorphism was assessed by a polymerase chain reaction-based method as previously described [41].

The MCP-1 A-2518G promoter polymorphism (rs699947) was detect by PCR reaction, amplification with specific primers: Primer F 5 CCGAGATGTTCCCA GCACAG 3, Primer R 5 ' CTGCTTTGCTTGTGCCTC TT 3 with $5 \mathrm{~min}$. at $96^{\circ} \mathrm{C}$ for the initial denaturation and 30 cycles of $1 \mathrm{~min}$. at $96^{\circ} \mathrm{C}, 1 \mathrm{~min}$. at $60^{\circ} \mathrm{C}$ and $1.5 \mathrm{~min}$. at $72^{\circ} \mathrm{C}$. Then, $5 \mathrm{~min}$. incubation at $72^{\circ} \mathrm{C}$ for final extension was performed. The restriction enzyme PvuII (MBI Fermentas, Italy; 5 U/sample) resolved three different band patterns, according to the three different genotypes; e.g. at $222 \mathrm{bp}$ and 705 bp (GG genotype), 222 bp, 705 bp and 927bp (GA genotype) or only 927 bp (AA genotype). The different bands pattern of the three genotype after agarose gel running, was shown in Figure 1.

\section{MCP-1 plasma levels measurement}

Bio-Plex Cytokine assay (Bio-Rad Laboratories, Hercules, CA, USA) was used to measure MCP-1 plasma levels. Assays were performed following the manufacturer's instructions (Multi beads assay BioPlex, BioRad). Briefly, a sets of fluorescently dyed beads loaded with capture monoclonal antibodies specific for MCP-1, were used. Plasma samples ( $50 \mu \mathrm{l} /$ well of four-fold diluted plasma) or standards were incubated with $50 \mu \mathrm{l}$ of pre-mixed beads into the wells of a pre-wet 96 well microlitre plate.

After incubation and washing, $25 \mu \mathrm{l}$ of fluorescent detection antibody mixture were added for $30 \mathrm{~min}$ and then the samples were washed and resuspended in assay buffer. High standard curves ranging from 2098.48 to $0.62 \mathrm{pg} / \mathrm{ml}$ for MCP-1 was performed as suggested by datasheet. Detection of MCP-1 levels was extrapolated using Bio-Plex Cytokine software.

\section{Statistical analysis}

The Hardy-Weinberg equilibrium was verified for the control group. Two-tailed Pearson's $x^{2}$ exact test was used to compare genotype and allele frequencies, the level of statistical significance was set at less than 0.05. A logistic regression model, adjusted for age and APOE $\varepsilon 4$ allele was used to evaluate the effect of A-2518G MCP-1 $\mathrm{SNP}$ on the risk of $\mathrm{AD}$, the risk of $\mathrm{MCI}$ conversion to $\mathrm{AD}$.
ANOVA test was used to compare the MCP-1 plasma levels in the tested groups.

\section{Abbreviations}

ACT: Alpha-1 antichymotrypsin; APOE: Apolipoprotein E; IL-1 b: Interlukin-1 beta; IL-6: Interleukin-6; TNFa: Tumor necrosis factor alpha; AD: Alzheimer's disease; CIND: Cognitive impairment but no dementia; CSF: Cerebro spinal fluid; MCl: Mild cognitive impairment; MCP-1: Monocyte chemoattractant protein-1; MMSE: Mini mental state examination.

\section{Competing interests}

The authors declare that they have no competing interests.

\section{Authors' contributions}

EP, MI, IC performed laboratory analysis and genotyping; MF enrolled AD patients and contributed to the study design; FL coordinated the application of statistical analysis of Conselice data base and contributed to design the clinical, epidemiological and genetic study; FL and EP have been involved in drafting the manuscript. All authors read and approved the final manuscript.

\section{Acknowledgements}

Study was supported by grant from Italian Ministry for University and Research. We thank Prof. Barbara Borroni for providing DNA samples of $\mathrm{MCl}$.

\section{Author details}

'DIMES, School of Medicine, University of Bologna, Via S. Giacomo 14, 40126, Bologna, Italy. ${ }^{2}$ Department of Neurology, IRCCS Multimedica, Milan, Italy.

Received: 29 November 2012 Accepted: 16 February 2013

Published: 21 February 2013

\section{References}

1. Meda I, Baron P, Scarlato G: Glial activation in Alzheimer's disease: The role of Abeta and it's associated proteins. Neurobiol Aging 2001, 22:885-893.

2. Breteler MMB, Claus JJ, van Duijn CM, Launer L, Hofman A: Epidemiology of Alzheimer's disease. Epidemiol Rev 1992, 14:59-82.

3. Licastro F, Porcellini E, Caruso C, Lio D, Corder EH: Genetic risk profiles for Alzheimer's disease: integration of APOE genotype and variants that up-regulate inflammation. Neurobiol Aging 2007, 28(11):1637-1643.

4. Licastro F, Porcellini E, Chiappelli M, Forti P, Buscema M, Ravaglia G, Grossi E: Multivariable network associated with cognitive decline and dementia. Neurobiol Aging 2010, 31:257-269.

5. Licastro F, Carbone I, lanni M, Porcellini E: Gene signature in Alzheimer's disease and environmental factors: the virus chronicle. J Alzheimers Dis 2011, 27:809-817.

6. Calingasan NY, Gibson GE: Vascular endothelium is a site of free radical production and inflammation in areas of neuronal loss in thiaminedeficient brain. Ann NY Acad Sci 2000, 902:353-356.

7. Teunissen $C E$, de Vente J, Steinbusch HW, De Bruijn C: Biochemical markers related to Alzheimer's dementia in serum and cerebrospinal fluid. Neurobiol Aging 2002, 23:485-508.

8. Hartmann T, Kuchenbecker J, Grimm MO: Alzheimer's disease: the lipid connection. J Neurochem 2007, 1:159-170.

9. Mangialasche F, Polidori MC, Monastero R, Ercolani S, Camarda C, Cecchetti $R$, Mecocci P: Biomarkers of oxidative and nitrosative damage in Alzheimer's disease and mild cognitive impairment. Ageing Res Rev 2009, 8:285-305.

10. McGeer PL, McGeer EG: Inflammation, autotoxicity and Alzheimer disease. Neurobiol Aging 2001, 22:799-809.

11. Porcellini E, Davis EJ, Chiappelli M, lanni E, Di Stefano G, Forti P, Ravaglia G, Licastro F: Elevated plasma levels of alpha-1-anti-chymotrypsin in agerelated cognitive decline and Alzheimer's disease: a potential therapeutic target. Curr Pharm Des 2008, 14:2659-2664.

12. Kim SM, Song J, Kim S, Han C, Park MH, Koh Y, Jo SA, Kim YY: Identification of peripheral inflammatory markers between normal control and Alzheimer's disease. BMC Neurol 2011, 12:11-51.

13. McGeer PL, McGeer EG: The inflammatory response system of brain: Implications for therapy of Alzheimer and other neurodegenerative diseases. Brain Res Rev 1995, 21:195-218. 
14. Peterson PK, Hu S, Salak-Johnson J, Molitor TW, Chao CC: Differential production of and migratory response to beta chemokines by human microglia and astrocytes. J Infect Dis 1997, 175:478-481.

15. Yamamoto M, Horiba M, Buescher JL, Huang D, Gendelman HE, Ransohoff RM, Ikezu T: Overexpression of monocyte chemotactic protein-1/CCL2 in beta-amyloid precursor protein transgenic mice show accelerated diffuse beta-amyloid deposition. Am J Pathol 2005, 166:1475-1485.

16. Galimberti D, Schoonenboom N, Scarpini E, Scheltens P: Dutch-Italian Alzheimer Research Group: Chemokines in serum and cerebrospinal fluid of Alzheimer's disease patients. Ann Neurol 2003, 53:547-548.

17. Corrêa JD, Starling D, Teixeira AL, Caramelli P, Silva TA: Chemokines in CSF of Alzheimer's disease patients. Arq Neuropsiquiatr 2011, 69:455-459.

18. Westin $K$, Buchhave $P$, Nielsen $H$, Minthon L, Janciauskiene S, Hansson O: $\mathrm{CCL} 2$ is associated with a faster rate of cognitive decline during early stages of Alzheimer's disease. PLoS One 2012, 7:e30525.

19. Galimberti D, Fenoglio C, Lovati C, Venturelli E, Guidi I, Corrà B, Scalabrini D, Clerici F, Mariani C, Bresolin N, Scarpini E: Serum MCP-1 levels are increased in mild cognitive impairment and mild Alzheimer's disease. Neurobiol Aging 2006, 27:1763-1768.

20. Corsi MM, Licastro F, Porcellini E, Dogliotti G, Galliera E, Lamont JL, Innocenzi PJ, Fitzgerald SP: Reduced plasma levels of P-selectin and L-selectin in a pilot study from Alzheimer disease: relationship with neuro-degeneration. Biogerontology 2011, 12:451-454.

21. Fenoglio C, Galimberti D, Lovati C, Guidi I, Gatti A, Fogliarino S, Tiriticco M, Mariani C, Forloni G, Pettenati C, Baron P, Conti G, Bresolin N, Scarpini E: MCP-1 in Alzheimer's disease patients: A-2518G polymorphism and serum levels. Neurobiol Aging 2004, 25:1169-1173.

22. Rovin BH, Lu L, Saxena R: A novel polymorphism in the MCP-1 gene regulatory region that influences $\mathrm{MCP}-1$ expression. Biochem Biophys Res Commun 1999, 259:344-348.

23. Jibiki T, Terai M, Shima M, Ogawa A, Hamada H, Kanazawa M, Yamamoto S, Oana $\mathrm{S}$, Kohno Y: Monocyte chemoattractant protein 1 gene regulatory region polymorphism and serum levels of monocyte chemoattractant protein 1 in Japanese patients with Kawasaki disease. Arthritis Rheum 2001, 44:2211-2212

24. Aguilar F, González-Escribano MF, Sánchez-Román J, Núñez-Roldán A: MCP-1 promoter polymorphism in Spanish patients with systemic lupus erythematosus. Tissue Antigens 2001, 58:335-338.

25. Szalai C, Duba J, Prohászka Z, Kalina A, Szabó T, Nagy B, Horváth L, Császár $A$ : Involvement of polymorphisms in the chemokine system in the susceptibility for coronary artery disease (CAD). Coincidence of elevated $\mathrm{Lp}(\mathrm{a})$ and MCP-1 $-2518 \mathrm{G} / \mathrm{G}$ genotype in CAD patients. Atherosclerosis 2001, 158:233-239.

26. Combarros O, Infante J, Llorca J, Berciano J: No evidence for association of the monocyte chemoattractant protein-1 (-2518) gene polymorphism and Alzheimer's disease. Neurosci Lett 2004, 360:25-28.

27. Pola R, Flex A, Gaetani E, Proia AS, Papaleo P, Di Giorgio A, Straface G, Pecorini G, Serricchio M, Pola P: Monocyte chemoattractant protein-1 (MCP-1) gene polymorphism and risk of Alzheimer's disease in Italians. Exp Gerontol 2004, 39:1249-1252.ù.

28. Ravaglia G, Forti P, Maioli F, Chiappelli M, Montesi F, Tumini E, Mariani E, Licastro F, Patterson C: Blood inflammatory markers and risk of dementia: The Conselice Study of Brain Aging. Neurobiol Aging 2007, 28:1810-1820.

29. Lambert JC, Heath S, Even G, Campion D, Sleegers K, Hiltunen M, Combarros O, Zelenika D, Bullido MJ, Tavernier B, Letenneur L, Bettens K, Berr C, Pasquier F, Fiévet N, Barberger-Gateau P, Engelborghs S, De Deyn P, Mateo I, Franck A, Helisalmi S, Porcellini E, Hanon O, European Alzheimer's Disease Initiative Investigators, De Pancorbo MM, Lendon C, Dufouil C, Jaillard C, Leveillard T, Alvarez V, Bosco P, et al: Genome-wide association study identifies variants at CLU and CR1 associated with Alzheimer's disease. Nat Genet 2009, 41:1094-1099.

30. Hollingworth P, Harold D, Sims R, Gerrish A, Lambert JC, Carrasquillo MM, Abraham R, Hamshere ML, Pahwa JS, Moskvina V, Dowzell K, Jones N, Stretton A, Thomas C, Richards A, Ivanov D, Widdowson C, Chapman J, Lovestone S, Powell J, Proitsi P, Lupton MK, Brayne C, Rubinsztein DC, Gill M, Lawlor B, Lynch A, Brown KS, Passmore PA, Craig D, et al: Common variants at ABCA7, MS4A6A/MS4A4E, EPHA1, CD33 and CD2AP are associated with Alzheimer's disease. Nat Genet 2011, 43:429-435.

31. Sokolova A, Hill MD, Rahimi F, Warden LA, Halliday GM, Shepherd CE: Monocyte chemoattractant protein-1 plays a dominant role in the chronic inflammation observed in Alzheimer's disease. Brain Pathol 2009, 19:392-398.
32. El Khoury J, Luster AD: Mechanisms of microglia accumulation in Alzheimer's disease: therapeutic implications. Trends Pharmacol Sci 2008, 29:626-632.

33. Boddeke H, Biber K, De Haas A, VanWeering H, De Jong E: Neuronal chemokines: versatile messengers in central nervous system cell interaction. Mol Neurobiol 2007, 36:137-151.

34. Petersen RC: Mild cognitive impairment as a diagnostic entity. J Intern Med 2004, 256:183-194.

35. Monastero R, Palmer K, Qiu C, Winblad B, Fratiglioni L: Heterogeneity in risk factors for cognitive impairment, no dementia: population-based longitudinal study from the Kungsholmen Project. Am J Geriatr Psychiatry 2007, 15:60-69.

36. McKhann G, Drachman D, Folstein M, Katzman R, Price D, Stadlan EM: Clinical diagnosis of Alzheimer's disease: report of the NINCDS-ADRDA Work Group under the auspices of Department of Health and Human Service Task Force on Alzheimer's Disease. Neurology 1984, 34:939-944.

37. American Psychiatric Association: Diagnostic and Statistical Manual of Mental Disorders: DSM-III-R, 3rd revised ed. Washington DC: American Psychiatric Association; 1987

38. Petersen RC, Doody R, Kurz A, Mohs RC, Morris JC, Rabins PV, Ritchie K, Rossor M, Thal L, Winblad B: Current concepts in mild cognitive impairment. Arch Neurol 2001, 58:1985-1992.

39. Ravaglia G, Forti P, Maioli F, Orlanducci P, Sacchetti L, Flisi E, Dalmonte E, Martignani A, Cucinotta D, Cavalli G: Conselice study: a population based survey of brain aging in a muncipality of the Emilia Romagna region: (A.U.S.L. Ravenna). Design and methods. Arch Gerontol Geriatr Suppl 2001, 7:313-324

40. Grimaldi LM, Casadei VM, Ferri C, Veglia F, Licastro F, Annoni G, Biunno I, De Bellis G, Sorbi S, Mariani C, Canal N, Griffin WS, Franceschi M: Association of early-onset Alzheimer's disease with an interleukin-1alpha gene polymorphism. Ann Neurol 2000, 47:361-365.

41. Licastro F, Pedrini S, Govoni M, Pession A, Ferri C, Annoni G, Casadei V Veglia F, Bertolini S, Grimaldi LM: Apolipoprotein E and alpha-1 -antichymotrypsin allele polymorphism in sporadic and familial Alzheimer's disease. Neurosci Lett 1999, 270:129-132.

doi:10.1186/1742-4933-10-6

Cite this article as: Porcellini et al:: Monocyte chemoattractant protein-1 promoter polymorphism and plasma levels in alzheimer's disease. Immunity \& Ageing 2013 10:6.

\section{Submit your next manuscript to BioMed Central and take full advantage of:}

- Convenient online submission

- Thorough peer review

- No space constraints or color figure charges

- Immediate publication on acceptance

- Inclusion in PubMed, CAS, Scopus and Google Scholar

- Research which is freely available for redistribution

Submit your manuscript at www.biomedcentral.com/submit
C) Biomed Central 